\title{
Synthesis of Paullone
}<smiles>O=C(Nc1ccccc1I)c1ccccc1</smiles>

A

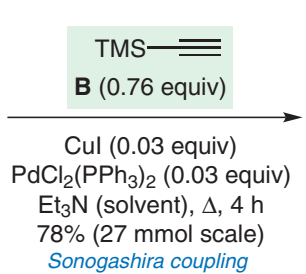

Sonogeshira coupling<smiles>CS(=O)(=O)Nc1ccccc1C#N</smiles>

C

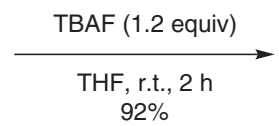

$92 \%$<smiles>C1CCCCC1</smiles>

$\mathrm{N}_{2} \mathrm{CHCO}_{2} \mathrm{Et}$ ( 1.05 equiv)

Cul (0.1 equiv)

$\mathrm{MeCN}$, r.t., $12 \mathrm{~h}$ $70 \%(2.3 \mathrm{mmol}$ scale $)$

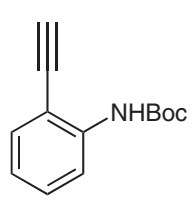

D

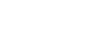

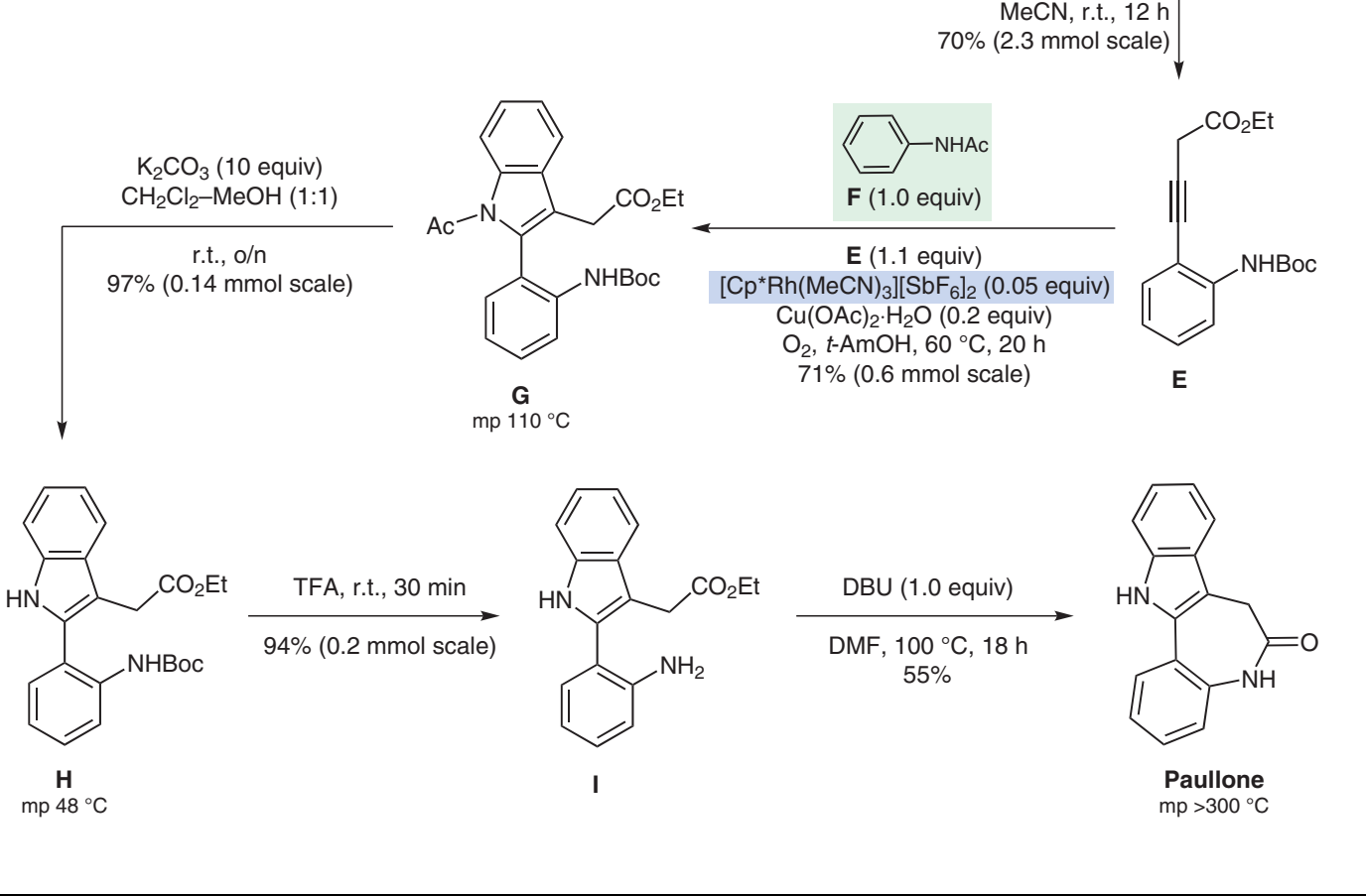

Significance: The paullones inhibit three diseaserelevant kinases, GSK-3, CDK-1, and CDK-5 as well as mitochondrial malate dehydrogenase. Most of them possess remarkable in vitro antiproliferative activity. The key step in the synthesis depicted is the oxidative annulation of acetanilide $(\mathbf{F})$ with the internal alkyne $\mathbf{E}$ catalyzed by a dicationic rhodium(III) complex to give the indole G. Molecular oxygen is the terminal oxidant.
Comment: A detailed investigation of the mechanism of the reaction established that a key step in the catalytic cycle is the irreversible and ratedetermining cleavage of the ortho $\mathrm{C}-\mathrm{H}$ bond in the acetanilide. The optimized reaction conditions were applied to the synthesis of 28 indoles. By using enamides in place of acetanilides, the reaction can be extended to the synthesis of pyrroles (16 examples). 